\title{
25 Years in a Nutshell - IMIA-NI, 1982 - 2007
}

\author{
M.Tallberg \\ Kuopio University, Department of Nursing Science, Kuopio, Finland
}

\begin{abstract}
Summary
Objective: When invited to give an overview of nursing informatics | found it natural to celebrate the $25^{\text {th }}$ anniversary of the International Medical Informatics Special Interests Group on Nursing Informatics (IMIA SIG NI) with a "mini history" from my own perspective Method: The method is historical. Sources are from the IMIA-NI web site, conference proceedings and programs, my private archive and reminiscences.

Results and conclusions: IMIA-NI has| "left its cradle" quite a while ago, and is now leading the nursing informatics world, thanks to its voluntary, enthusiastic and devoted leaders, WG chair persons, and national members. The newly reinforced executive also works hard to disseminate nursing informatics to the third world.

\section{Keywords}

Nursing informatics, nursing history, IMIA-NI, terminology

Geissbuhler A, KulikowskiC, editors. IMIA Yearbook of Medical Informatics 2008. Methods Inf Med 2008; 47 Supp 1 1:173-8
\end{abstract}

\section{Introduction}

Nurses' active interest in automating their notes and other paperwork can be traced back to the 1960's. Fifty-eight references to articles with titles referring to nursing and computers were found in the International Nursing Index for1966 (its first year). The distribution was not yet worldwide, but the US, Canada, Japan, Korea, the UK, and Sweden were represented [1]. In the 1970 's the first nursing and computer conferences were held in the US [2], while nurses had already presented papers at the Medinfo conferences [3], and the nurse informatician was born [4]. The Northern Nurses Association put out a call in 1978 [5] for a meeting on how the use of computers in health care would affect nurses' roles. As a member of the Finnish Nurses Association board I was asked to survey the state of the art in Finland and was fascinated by the early trials in occupational health and primary care [6]. At the meeting in Stockholm I met Ulla Gerdin, since then one of my best friends. Back home I joined the small Finnish Medical Informatics Association and started to teach my students at the nursing school about the use of computers in health care.

\section{The London Conference - 1982}

In England nurses started a computer project group in 1973, but money and greater support was needed for arranging a conference. With the help of William "Bud" Abbott a Director of Computing and Barry Barber a Chief Management Scientist, the IMIA General Assembly was convinced that it was time for a conference on nursing and computing. A combined organizing and program committee, with the Director of Nursing services of London Hospital, Maureen Scholes, as chairman, Bud Abbott as treasurer and Barry Barber as secretary with further ten members, started its work [3].

It was decided on an open conference called "The Impact of Computers on Nursing" followed by an invitational smaller workshop sponsored by the open conference, an arrangement that is still practiced at IMIA-NI conferences. I got to hear of the conference by "the jungle telegraph" and wrote to Maureen Scholes. She invited me to a pre-conference visit at London Hospital, where the nurses' work already was supported by computers. The accommodation was nicely thought for nurses with smaller means, the quarters in the university hall were good with a substantial breakfast, and it was rather fun to queue together with the students for a shower in the morning. The site for the event was the spectacular Church House at Westminster - a famous old circular building in the heart of London - with a well-attended exhibition in the nearby Central Methodist Hall. The conference attracted 550 delegates who listened to $22 \mathrm{pa}-$ per presentations [3]. 
The workshop with 59 invited "experts" took place in Harrogate and to get as many countries represented as possible, the workshop was linked to a compulsory paper presentation by each participant. The post-conference papers and discussions were then edited and published together with the conference papers, a glossary and a bibliography [7]. In his conclusions to the proceedings Barry Barber states:

"The human needs of individuals must not get lost in the elegance of systems... nurses must control nursing and computing systems must not lure them into making decisions incompatible with good nursing practice."[7 p.551]

\section{IMIA Working Group 8, Nur- sing Informatics}

After the London conference a report was sent to the International Medical Informatics Association (IMIA) General Assembly meeting in Melbourne, Australia in September 1982, which formally authorized the group as Working Group 8 - Nursing Informatics.

The WG8 held its first General Assembly meeting at the Medinfo in Amsterdam 1983. Now the interim chairman Maureen Scholes was appointed chairman, Kathryn Hannah, Canada vicechairman, and Elly Pluyter-Wenting, The Netherlands secretary. In the first bylaws the following aims were outlined:

"• to explore the scope of nursing informatics for providing patient care, nursing education and the greater use of resources in the world wide context,

- to provide informatics meetings and to develop this field,

- to support the development of nursing informatics in the member countries of IMIA,

- to encourage the publication of re search, development and review material,

- to develop outlines for educational courses in nursing informatics."[7] The IMIA member countries were asked to nominate their representative to WG8 preferably in conjunction with national nursing associations. As seed money IMIA granted us 1000 Swiss Francs. From the start WG8 was invited to appoint members to the IMIA WGs on data protection and hospital information systems. Beginning with the Medinfo 1989 WG8 has been represented in the scientific program committees of all Medinfo conferences. Work and co-work had started [3].

\section{The Calgary Conference}

The Calgary conference "Building bridges to the future" in spring 1985 was in reality the first WG8 conference. It started with two pre-sessions, one was an introduction for novices, the other provided the opportunity to get to know local facilities. Education and training competed with information systems in having most papers. Sue Grobe gave me a private demonstration in the use of NEMAS (Nursing Education Module Authoring System), I thought it useful but it was ahead of its time. The conference had a strong emphasis on ethics and data protection, $10 \%$ of the papers, and I will never forget Gerd Griesser's presentation. Some of the nurses had expressed maybe a bit too much optimism in what computers could do for nurses, which provoked Werner Schneider to tell us not to go on as computer-Salvationists. We all laughed, but it was a good lesson. The post-conference slogan "Challenges for the future" mirrored many of today's still present challenges e.g. the integrated patient record and a nursing language [8].

\section{MIE and Medinfo Conferences}

At MIE-85 in Helsinki, Maureen Scholes and I chaired a nursing session which became a turning-point for the understanding of informatics significance for nursing in Finland. Here I met the strong nursing informatics supporter Marion Ball for the first time [9]. The WG8 was invited to arrange a "nursing day" at MIE- 87 in Rome, Italy and I was appointed to co-ordinate the day at the conference. After the Helsinki event Sue Grobe followed me to our summer house. There sitting on our sauna terrace Sue sketched - on a paper plate - a program for the Rome session. My knowledge of the Italian language and habits were really tested during the conference organization, but the "nursing day" was a success [10]. This experience showed me that there was a need for a nursing group even within the European Federation for Medical Informatics (EFMI). At the following EFMI meeting in Oslo 1988 the idea was approved and I was appointed chairman of the nursing group WG5. Since then the both nursing working groups has had a near collaboration in changing ideas and arranging joint workshops at MIE and Medinfo conferences. In 1986 the Medinfo took us to Washington D.C. where more than 30 nursing papers and demonstrations were presented as an integral part of the program. The opportunity to learn to know many more American colleagues, among them Virginia Saba and Patti Brennan was most rewarding. The visit to the National Library of Medicine opened a new world for me - they had everything![11] At the WG8 General Assembly Kathryn Hannah took over the leadership from Maureen Scholes, Elly Pluter-Wenting was appointed vicechair and Judy Ronald secretary [3]. 
cation and workload, while education still maintained its preeminent position [19]. In summarizing the "Healthcare information technology: implications for care" post conference workshop Kathleen McCormick notes:

"...smarter nurses will use technology to practice nursing more efficiently and may reduce costs, or at best balance the high costs of rising salaries and technology costs."

She foresaw today's demands on nurses early [20].

\section{NI'94 San Antonio, Texas, USA}

San Antonio, Texas hosted the fifth conference "Nursing in a Technological Era" in 1994 with about 1000 participants from 32 countries. 400 abstracts received resulted in over 200 different presentations. A nursing minimum data set, standards, and vocabularies were strongly represented and knowledge retrieval did a breakthrough. Susan Grobe surprised us with an unusual large and interesting exhibition, and the graduate student poster competition made its first appearance during this conference [21]. Sue Bakken Henry started the post conference by giving a partly historical overview of the theme "Informatics: Essential Infrastructure for Quality Assessment and Improvement in Nursing". Group discussions resulted in some recommendations, but more new questions for further research were arising. For the first time a number of Post conference papers were fully refereed and published in JAMIA [22].

\section{NI'1997 Stockholm, Sweden}

In 1997 it was Sweden's turn to arrange the sixth conference in Stockholm "The
Impact of Nursing Knowledge on Health Care Informatics" attended by 540 health care professionals from 32 countries. As chairman for the scientific committee I had the great joy to work closely together with Ulla Gerdin. To speak about "The theoretical basic for nursing informatics" we had invited Imogene M. King, professor in nursing science. Michel J. Ackerman assistant director for High Performance and Communications at the National Library of Medicine gave an unforgettable presentation of the "Visible $\mathrm{Hu}$ man Project". This time about $20 \%$ of papers and panel discussions dealt with nursing language or terminology [23]. At the post conference in Lidingö our theme was "Combining clinical guidelines and patient preferences using health informatics". Many interesting papers were presented, of which Rita Zielstorff's concluded: "Technology holds great promise to make evidencebased practice a reality, leading to the ultimate goal of high-quality, cost-efficient patient care."

Five groups engaged in vigorous discussions, when debating ethical views in the constellation of patients preferences versus clinical guidelines. Recommendations from the post conference were sent to the ICN [24].

\section{NI'2000 Auckland, New Zealand}

"One Step Beyond: The Evolution of Technology and Nursing" the NI'2000 took place in Auckland, New Zealand under the leadership of Michelle Honey and Robyn Carr. The themes for the eighteen workshops at the pre-conference had a wide distribution from "Protecting the Confidentiality" to the "Use of the Unified Modeling Language (UL)." Informatics history was an ac- tual theme and in her keynote address Kathryn Hannah started from the very beginning finishing with views on the future, giving us as a piece of advice:

"With the arrival of reliable software and more graphical user interfaces, the focus of information management technology must be the patient."[25]

The IMIA-NI history "International Nursing Informatics: A history of the first forty years 1960 - 2000" by Maureen Scholes, Marianne Tallberg and Elly Pluyter-Wenting was presented at the conference [3]. For the post-congress the participants moved to Roturoa, a fascinating place where mud bubbles up from the ground and hot water pillars shoots up to the sky. The overall theme was evidence - how to build, how to access and how to apply it. After the paper presentations group work was done to apply Clinical Pathways and Outcomes - using evidence based practice in acute care and in respective primary care and community and home health care [26].

\section{NI'2003 Rio de Janeiro, Brazil}

In 2003 Brazil hosted the IMIA-NI conference "e-Health for all: designing the nursing agenda for the future." Together with the Honorary chair Virginia Saba, Heimar Marin succeeded in encouraging a great number of informatics interested nurses to participate in the event. The conference started with a rich selection of tutorials and evening workshops. Naturally I always will remember the colorful carnival opening when I was made honorary member of the IMIA-NI group and presented with a beautiful objet d'art. Looking for actual themes in papers, panels and demos presented I found that approximately $23 \%$ was about educa- 
tion and training, $14 \%$ about terminology, classification and data sets and $6 \%$ about decision support.[27] The goal of the post conference was to recommend the agenda for patient safety in the field of health informatics. Sixteen paper were presented as a start for the group work which results are presented in the proceedings "Improving Patient Safety with Technology "[28].

\section{NI'2006 Seoul, Korea}

In Seoul, Korea, Hyeoun-Ae Park wished us a warm welcome to the ninth IMIA-NI conference 2006, "ConsumerCentered, Computer-Supported Care for Healthy People." We got a good start for the meeting when Roy Simpson in his keynote speech guided us into a "Consumer smart world". Among the broad selection of papers, panels and workshops $11 \%$ dealt with electronic patient records and 13\% used the Internet in some way [29]. Peter Murray writes in the Post Conference proceedings:

"The purpose of the NI2006 Post Congress Conference was to explore a range of possibilities...all of which need to be considered in order to move towards a future we do seek to envisage or influence".

My recommendation is - read the book [30].

\section{IMIA-NI in the 21st Century}

IMIA-NI has been open to co-work with other organizations. Co-operation between two of the IMIA-NI WGs and the International Council of Nursing (ICN) resulted in the ISO-Model International Standard ISO 18104 which was approved in 2003. The International Nursing Minimum Data Set (iNMDS) launched in 2000 is another collaboration project with ICN. IMIA-NI activists has also participated in the SNOMED CT Convergent Terminology Group for nursing for enhance the coverage of SNOMED CT ${ }^{\circledR}$ for the domain of nursing.

The NI working groups are changing in number and activities as the needs and activities of all its members change. An example is the History group which first wrote the group's history published in the year 2000 and in May 2007 handed over the IMIA-NI archive to the National Archive of Medicine, which has promised to keep it. We are very grateful to NLM for this. Another example is the IMIA-NI Management group which arranged the First Nursing Informatics Leadership's conference in 2007 in Brisbane in conjunction with Medinfo.

The IMIA-NI principles; Leadership, Patient and Public Focus, Ethics, Innovation, and Evidence Based are presented in the Strategic Plan for 20042007. The IMIA-NI activities have increased, making it necessary to amend the bylaws in 2006. Now the IMIA-NI executive consists of the chair assisted by four vice-chairs of which everyone has their own field of responsibility. The most important of the IMIA-NI activities are the tri-annual conferences for which new regulations for the bidding procedure were approved in 2003 [31]. The next IMIA-NI conference will take place in my home town Helsinki, Finland in 2009 and I look forward to welcoming every one to this event [32].

\section{A Vision}

I would like to finish my very subjective IMIA-NI "mini history" by taking the liberty of quoting the vision of the IMIA-NI group:
"IMIA-NIs vision is to provide leadership world wide in the development, implementation, and evolution of Nursing Informatics, as an inter-related component of Health Informatics, to ensure Nursing Informatics supports the nursing profession, organizations, communities and patients in pursuing and achieving health for all."[31]

\section{References}

1. The International Nursing Index. New York: American Journal of Nursing. 1966.

2. Saba VK, McCormick KA. Historical perspectives of nursing and computers. In: Essentials of computers for nursing. 2nd ed. New York: American Journal of Nursing Company; 1966.

3. Scholes M, Tallberg M, Pluyter-Wenting E, editors. International nursing informatics: A history of the first forty years 1960 - 2000. Swindon: The British Computer Society; 2000

4. Tallberg M. The Finnish informatics nurse, her job and education against a background of international development. In: Mantas J, editor. Advances in health telematics education. A Nightingale perspective. Studies in Health Technology and Informatics Vol. 51. Amsterdam: IOS Press; 1998. p. $35-40$.

5. Söderholm C. ATK: n hyväksikäyttö sairaanhoidossa. [The use of ADP in nursing]. Sairaanhoitaja/Sjuksköterskan. 1978;54(10):36.

6. Jokinen Y. Projektin käynnistäminen WATTI raportti N:o 1. [Start of the project. Watti report no. 1] Kuopio: Kuopion korkeakoulu; 1979.

7. Scholes M, Bryant Y, Barber, B, editors. The impact of computers on nursing - an international review. Proceedings of the IFIP-IMIA Workshop on the Impact of Computers on Nursing; 1982 September 8-9; London and September 10-15; Harrogate, England. Amsterdam: North-Holland; 1983.

8. Hannah KJ, Guillemin EJ, Conklin DN, editors. Proceedings of the IFIP-IMIA International Symposium on Nursing Uses of Computers and Information Science; 1985 May 1-3; Calgary, Alberta, Canada. Amsterdam: North-Holland; 1985.

9. MIE 85 final program. Helsinki $; 1985$.

10. MIE 87 final program. Rome; 1987

11. Medinfo 86. Fifth world congress on medical informatics. Advance program. Washington D.C.; 1986.

12. Peterson HE, Gerdin-Jelger U, editors. Preparing nurses for using information systems: Recommended informatics competencies. New York: National League for Nursing; 1988.

13. Daly N, Hannah KJ, editors. Nursing and computers. Proceedings of the Third international symposium on nursing use of computers and information science; 1988 June 20-23; Dublin, Ireland. St.Louis: CV. Mosby Co; 1988 .

14. Ozbolt JG, Vandewal D, Hannah KJ, editors. 
Decision support systems in Nursing. Including Proceedings from the Third International Symposium on Nursing Use of Computers and Information Science; 1988 June 24-27; Killarney, Ireland. St.Louis: CV. Mosby Co; 1990.

15. IMIA-SIG NI bylaws.

16. General Assembly meeting minutes 1998

17. IMIA-NI Newsletter 1994, 1995, 1996.

18. Turley JP, Newbold SK, editors. Pre-conference proceedings of Nursing Informatics '91. In: Lecture Notes in Medical Informatics, editors. Rienhoff O, Lindberg DAB. 41. Berlin:Springer -Verlag; 1991.

19. Hovenga EJS, Hannah KJ, McCormick KA, Ronald JS, editors. Nursing Informatics'91. Proceedings of the Fourth International Conference on Nursing Use of Computers and Information Science; 1991 April 14-17; Melbourne, Australia. In: Rienhoff O, Lindberg DAB, editors. Lecture Notes in Medical Informatics, 42. Berlin:Springer-Verlag; 1991

20. Marr PB, Axford RL, Newbold SK, editors. Nursing Informatics'91. Proceedings of the Post Conference on Health Care Information Technology: Implications for Change; In: Rienhoff O, Lindberg $D A B$, editors. Lecture Notes in Medical Informatics, 46. Berlin: Springer -Verlag; 1991.

21. Grobe SJ, Pluyter-Wenting ESP, editors. Nursing informatics: An international overview for nursing in a technological era. Proceedings of the fifth IMIA international conference on nursing use of computers and information science; 1994 June 17-22; San Antonio, Texas, USA, Amsterdam: Elsevier; 1994.

22. Bakken HS, Holzemer WL, Tallberg M, Grobe SJ, editors. Informatics: The infrastructure for quality assessment improvement in nursing. Proceedings of the Fifth International Nursing Symposium Postconference; 1994 June 24-25; Austin, Texas, USA. San Francisco: UC Nursing Press; 1994.

23. Gerdin U, Tallberg M, Wainwright P, editors. Nursing Informatics. The Impact of Nursing Knowledge on Health Care Informatics. Proceedings of the Sixth Nursing Informatics Conference; 1997 September 26-October 1; Stockhom, Sweden. Studies in Health Technology and Informatics. Vol. 46. Amsterdam: IOS Press; 1997.

24. Ehnfors M, Grobe, Tallberg M, editors. Nursing Informatics. Combining clinical practice guidelines and patient preferences using health informatics. Proceedings of the Sixth International Nursing Informatics Symposium Post-Conference; 1997 October 1-4; Lidingö, Sweden. Stockholm: Spri; 1998.

25. Saba V, Carr R, Sermeus W, Valverde Rocha P, editors. One Step Beyond: The Evolution of Technology and Nursing. Proceedings of the 7th IMIA International Conference on Nursing Use of Computers and Information Science; 2000 April 28-May 3; Auckland, New Zealand. Auckland: Adis; 2000.

26. Mc Arthur J, Carr R, Westbrooke L, Honey M, Bakken S, editors. Proceedings of the NI2000 Post Congress Workshop; 2000 May 3-6; Roturoa, New Zealand. Auckland: Premier Print; 2001.

27. Marin HF, Marques EP, Hovenga E, Goossen W, editors. E-Health for all: designing the nursing agenda for the future. Proceedings of the 8th International Congress in Nursing Informatics; 2003
June 20-25; Rio de Janeiro. Rio de Janeiro: epapers. 2003

28. Marin HF, Mendonca E, Pedreira M, Marques EP, editors. Improving patient safety with technology. Proceedings of the NI 2003 Post Congress Workshop; 2003 June 25-28; Mangaratiba, Rio de Janeiro, Brazil. Rio de Janeiro: e-papers; 2003.

29. Park H-A, Murray P, Delaney C, editors. ConsumerCentered Computer-Supported Care for Healthy People. Proceedings of NI2006 The 9th International Nursing Informatics Conference; 2006 June 1014; Seoul, Korea. In: Studies in Health Technology and Informatics. Vol. 122. Amsterdam: IOS Press; 2006.

30. Murray PJ, Park HA, Erdley WS, Kim J, editors. Nursing Informatics 2020: Towards defining our own future. Proceedings of NI2006 Post Congress Conference; 2006 June 14-17; Phoenix Park, Pyung-Chang, Kangwon-do, Korea. In: Studies in Health Technology and Informatics. Vol. 128. Amsterdam: IOS Press; 2007.

31. http://www.imiani.org/

32. www.ni2009.org

\section{Correspondence to:}

Marianne Tallberg

Enåsvägen 10 c, 00200 Helsinki, Finland

Tel: $+358-9-675887$

Fax: +358-9-6821129

E-mail:marianne.tallberg@kolumbus.fi 